\title{
STUDI PEMBERIAN ANTIPSIKOTIK TERHADAP BEBERAPA JENIS SKIZOFRENIA DI RSJD ATMA HUSADA MAHAKAM SAMARINDA
}

\author{
Rina Yemima Maylani*, Jaka Fadraersada, Adam M. Ramadhan \\ ${ }^{1}$ Laboratorium Penelitian dan Pengembangan Kefarmasian "Farmaka Tropis", \\ Fakultas Farmasi, Universitas Mulawarman, Samarinda, Indonesia \\ ${ }^{2}$ Kelompok Bidang Ilmu Farmasi Klinik dan Komunitas, Fakultas Farmasi, \\ Universitas Mulawarman, Samarinda, Indonesia \\ *Email: yemima.rym@gmail.com
}

\begin{abstract}
Schizophrenia is a severe brain and mind disorder that can make patient undergo hallucination, delusion and behavior. The purpose of this study was to determine the type of schizophrenia that many patients experience and the relationship between the types of schizophrenia and the administration of drugs to schizophrenic patients in inpatient institutions at the Atma Husada Mahakam Samarinda Regional Mental Hospital. This study is an observational study with prospective data collection techniques. The sampling technique was total sampling hospitalized at RSJD Atma Husada Mahakam Samarinda. Data were analyzed descriptively in the medical record section. Data collection was carried out inpatient at Atma Husada Mahakam Hospital in Samarinda from August to October 2018. The results showed that the treatment pattern in schizophrenia patients was not more detailed given Risperidone in single therapy and a combination of Risperidone + Clozapine was given. The most widely given antipsychotic hebefrenic schizophrenia is Haloperidol in single therapy. Paranoid schizophrenia is given more by Haloperidol in single therapy, and Risperidone + Clozapine in combination therapy. Schizophrenia simplex therapy given is Clozapine, and in Schizophrenia which is not classified as therapy given is Haloperidol and Chlorpromazine.
\end{abstract}

Keywords: Antipsychotics, haloperidol, paranoid, schizophrenia, total sampling

\begin{abstract}
ABSTRAK
Skizofrenia merupakan penyakit gangguan otak parah di mana orang menginterpretasikan realitas secara abnormal gangguan pikiran berupa halusinasi, delusi, dan perilaku. Tujuan penelitian ini adalah untuk mengetahui jenis Skizofrenia yang banyak dialami pasien dan keterkaitan jenis Skizofrenia dengan pemberian obat terhadap pasien Skizofrenia di instansi rawat inap Rumah Sakit Jiwa Daerah Atma Husada Mahakam Samarinda. Penelitian ini adalah penelitian observasional dengan teknik pengambilan data secara prospektif. Teknik pengambilan sampel adalah Total sampling dirawat inap diRSJD Atma Husada Mahakam Samarinda. Data dianalisis secara deskriptif pada bagian catatan rekam medik. Pengambilan data dilakukan dirawat inap di RSJD Atma Husada Mahakam Samarinda periode Agustus-Oktober 2018. Hasil penelitian didapatkan pola pengobatan
\end{abstract}


pada pasien Skizofrenia tak terinci lebih banyak diberikan Risperidone pada terapi tunggal dan kombinasi Risperidone + Clozapine yang banyak diberikan. Skizofrenia hebefrenik antipsikotik yang banyak diberikan adalah Haloperidol pada terapi tunggal. Skizofrenia paranoid lebih banyak diberikan Haloperidol pada terapi tunggal, dan Risperidone + Clozapine pada terapi kombinasi. Skizofrenia simpleks terapi yang diberikan adalah Clozapine, dan pada Skizofrenia yang tak tergolongkan terapi yang diberikan adalah Haloperidol dan Chlorpromazine.

Kata Kunci: Antipsikotik, haloperidol, paranoid, skizofrenia, total sampling

DOI: https://doi.org/10.25026/mpc.v8i1.333

\section{PENDAHULUAN}

Menurut data WHO (2016), terdapat sekitar 21 juta orang terkena Skizofrenia di Dunia, sedangkan menurut Riskesdas 2013 prevalensi Skizofrenia mencapai sekitar 400.000 orang atau sebanyak 1,7 per 1.000 penduduk di Indonesia $^{[3]}$.

Menurut Organisasi Kesehatan Dunia (WHO), Kesehatan jiwa merupakan suatu keadaan dimana seseorang terbebas dari gangguan jiwa, dan memiliki sikap positif untuk menggambarkan tentang kedewasaan serta kepribadiannya ${ }^{[14]}$. Gangguan jiwa tidak menyebabkan kematian secara langsung, tetapi ganggguan ini dapat membuat penderita menjadi tidak produktif dan bergantung pada orang lain, sehingga menyebabkan penderitaan berkepanjangan baik bagi penderita, keluarga, masyarakat maupun Negara ${ }^{[16]}$. Salah satu jenis gangguan jiwa psikosis fungsional adalah Skizofrenia. Skizofrenia ditandai dengan gejala-gejala positif dan negatif, gejala positif seperti pembicaraan kacau, delusi, halusinasi, gangguan kognitif dan persepsi. Gejala negatif seperti Avolition (menurunnya minat dan dorongan), berkurangnya keinginan bicara dan miskinnya isi pembicaraan, afek yang datar, serta terganggunya relasi personal ${ }^{[9]}$.

Terapi yang biasa dilakukan pada penderita penyakit Skizofrenia adalah
Antipsikotik. Antipsikotik dibagi dalam dua kelompok besar, yaitu Antipsikotik Tipikal (antagonis reseptor dopamine), contoh obat seperti Haloperidol, Klorpromazin, Perphenazine, Trifluoperazine, Fluphenazine, Thioridazine, serta Pimozide. dan Antipsikotik Atipikal (antagonis serotonin dopamine) contoh obat seperti Clozapine, Olanzapin, Risperidone, Aripiprazole, Zotepine, Quetiapine, dan Sulpiride ${ }^{[10]}$.

Dalam Pedoman Penggolongan dan Diagnosis Gangguan Jiwa di Indonesia (PPDGJ) jenis Skizofrenia terbagi menjadi 9 jenis yaitu : Paranoid, hebefrenik, katatonik, tak terinci, pascaskizofrenia, residual, simpleks, skizofrenia lainnya (skizofreniform, skizofrenia laten,dan skizoafektif) dan yang tak tergolongkan ${ }^{[1][9]}$.

Penelitian ini ingin mengetahui karakteristik pasien, jenis Skizofrenia yang banyak dialami pasien dan keterkaitan jenis Skizofrenia dengan pemberian obat antipsikotik terhadap pasien Skizofrenia di instalasi rawat inap RSJD Atma Husada Mahakam Samarinda.

\section{METODE PENELITIAN}

Metode Penelitian yang digunakan ialah Observasional, yaitu penelitian yang dilakukan dengan tujuan utama untuk penjabaran data dan membuat gambaran 
atau deskriptif tentang suatu keadaan secara objektif. Populasi penelitian adalah seluruh pasien Skizofrenia di instalansi rawat inap RSJD Atma Husada Mahakam Samarinda. Metode pengambilan sampel yang digunakan adalah Total sampling. Penelitian ini dilakukan secara prospektif pada data rekam medik pasien Skizofrenia periode Agustus sampai Oktober 2018 di instalansi rawat inap RSJD Atma Husada Mahakam Samarinda.

Pengumpulan data dilakukan dengan mencatat beberapa parameter yaitu usia, jenis kelamin, pekerjaan, jenis skizofrenia dan terapi obat-obatan pasien. Data dianalisis secara deskriptif disajikan dalam bentu persentase dan ditampilkan dalam bentuk tabulasi.

Tabel 1. Data Karakteristik Pasien Skizofrenia Rawat Inap di RSJD Atma Husada Mahakam

\begin{tabular}{|c|c|c|}
\hline Karakteristik Pasien & Jumlah (n) & Persentase $\%$ \\
\hline \multicolumn{3}{|l|}{ Jenis Kelamin } \\
\hline Laki-laki & 67 & 71,3 \\
\hline Perempuan & 27 & 28,7 \\
\hline \multicolumn{3}{|l|}{ Usia } \\
\hline \multicolumn{3}{|l|}{ Laki-laki } \\
\hline 12-16 tahun & 2 & 2,1 \\
\hline 17-25 tahun & 15 & 15,95 \\
\hline 26-35 tahun & 23 & 24,5 \\
\hline 36-45 tahun & 15 & 15,95 \\
\hline 46-55 tahun & 9 & 9,6 \\
\hline 56-65 tahun & 2 & 2,1 \\
\hline$>66$ tahun & 2 & 2,1 \\
\hline \multicolumn{3}{|l|}{ Perempuan } \\
\hline 12-16 tahun & 0 & 0 \\
\hline 17-25 tahun & 2 & 2,1 \\
\hline 26-35 tahun & 7 & 7,44 \\
\hline $36-45$ tahun & 11 & 11,7 \\
\hline 46-55 tahun & 4 & 4,2 \\
\hline 55-65 tahun & 2 & 2,1 \\
\hline$>66$ tahun & 1 & 1,06 \\
\hline \multicolumn{3}{|l|}{ Pekerjaan } \\
\hline Swasta & 22 & 23,4 \\
\hline Pelajar & 18 & 19,14 \\
\hline Tidak Bekerja & 18 & 19,14 \\
\hline IRT & 15 & 15,6 \\
\hline Petani & 9 & 9,57 \\
\hline Bekerja Tidak Tetap & 9 & 9,57 \\
\hline PNS & 2 & 2,08 \\
\hline Nelayan & 1 & 1,04 \\
\hline \multicolumn{3}{|l|}{ Diagnosa } \\
\hline Tak Terinci & 64 & 68 \\
\hline Paranoid & 15 & 16 \\
\hline Hebefrenik & 13 & 14 \\
\hline Simpleks & 1 & 1 \\
\hline Yang Tak Terdefinisi & 1 & 1 \\
\hline
\end{tabular}




\section{HASIL DAN PEMBAHASAN}

\section{Karakteristik Pasien Skizofrenia}

Penelitian ini dilakukan pada pasien Skizofrenia yang dirawat inap di RSJD Atma Husada Mahakam data yang diperoleh meliputi karakteristik dari pasien Skizofrenia meliputi jenis kelamin, usia, pekerjaan dan jenis Skizofrenia, untuk mengetahui pengaruh karakteristik tersebut terhadap pasien Skizofrenia yang lebih berisiko untuk menderita penyakit Skizofrenia.

Faktor jenis kelamin sering dikatakan sebagai salah satu faktor resiko terjadinya penyakit Skizofrenia. menurut Sutardjo, 2015 ${ }^{[20]}$ dalam buku Pengantar Psikologi Abnormal hal: 161 menyimpulkan wanita yang dirumahsakitkan lebih jarang dan memiliki periode waktu yang lebih singkat daripada laki-laki. Hal ini dikarenakan laki-laki secara sosial merupakan penopang utama dalam rumah tangga dan memiliki tingkat tekanan hidup yang lebih tinggi dibandingkan perempuan sehingga menimbulkan stress $^{[8]}$. Siklus stress terjadi karena kadar opiod diotak rendah, dan secara otomatis akan memicu peningkatan dopamine, sehingga meningkatkan kewaspadaan dan timbul kegelisahan menyebabkan terjadinya Skizofrenia ${ }^{[4]}$.

Berdasarkan penelitian yang dilakukan terhadap 94 pasien yang dirawat inap di RSJD Atma Husada Mahakam Samarinda maka didapatkan bahwa subjek penelitian berjenis kelamin laki-laki lebih banyak yaitu $71,3 \%$, dibanding perempuan $28,7 \%$. Hal ini dikarenakan jenis kelamin laki-laki biasanya memiliki agresifitas sangat tinggi sehingga sulit ditangani jika hanya dirawat dirumah, sedangkan agresifitas perempuan penderita Skizofrenia masih dapat ditangani oleh keluarga ${ }^{[5]}$. Selain itu wanita memiliki hormon estrogen yang bekerja sebagai antidopaminergik sehingga menghambat pelepasan dopamine dinukleus akumben ${ }^{[13]}$.
Hormon oksitosin pada wanita juga dapat mengurangi gejala psikosis dengan menghambat dopamine di mesolimbik dan memperbaiki pola pikir serta persepsi sosial ${ }^{[19]}$. Skizofrenia pada laki-laki biasanya timbul antara usia 15-25 tahun, sedangkan pada wanita antara 25-35 tahun ${ }^{[11]}$. Berdasarkan hasil persentase berdasarkan usia pada pasien laki-laki yang lebih banyak menderita Skizofrenia yaitu pasien pada pasien dewasa yang berusia 26 sampai 35 tahun dengan persentase $24,5 \%$ dan paling sedikit pada usia $>66$ tahun yaitu $2,12 \%$. Sedangkan pada pasien perempuan yang lebih banyak menderita Skizofrenia yaitu pasien yang berusia 36 sampai 45 tahun dengan persentase $11,7 \%$. Hal ini disebabkan onset terjadinya penyakit Skizofrenia biasanya pada masa awal; dewasa, dan akhir dewasa, jarang terjadi pada sebelum remaja atau setelah umur 40 tahun $^{[10]}$. Dikarenakan rentang tersebut merupakan usia produktif yang dipenuhi dengan banyak faktor pencetus stress dan memiliki beban tanggung jawab yang besar.

Berdasarkan hasil penelitian persentase pasien Distribusi pekerjaan pasien Skizofrenia yang terbanyak pada penelitian ini adalah swasta yaitu $25 \%$. hal ini dikarenakan kondisi tekanan sosial ekonomi yang tidak sehat, misalnya pendapatan jauh lebih rendah dari pengeluaran, kebangkrutan usaha, konflik dengan rekan sekerja, konflik antara atasan dan bawahan, dan lain sebagainya yang dapat menjadi sumber stress pada diri seseorang.

Tipe Skizofrenia terbanyak adalah tipe Skizofrenia Tak terinci yaitu 63,54\%. Tipe ini mempunyai gejala positif yang menonjol, memenuhi kriteria skizofrenia tetapi tidak dapat digolongkan pada skizofrenia yang lain. Tipe paranoid merupakan tipe yang terbanyak kedua yaitu $19,8 \%$. Tipe ini memiliki ciri utama yaitu adanya keyakinan yang tidak rasional (waham) yang mencolok atau halusinasi auditorik dalam konteks 
terdapat fungsi kognitif dan afek yang masih terjaga ${ }^{[1]}$, selanjutnya tipe hebefrenik $(14,58 \%)$. Ciri utama tipe ini adalah pembicaraan kacau dapat disertai kekonyolan dan tawa yang tidak dapat berkaitan dengan isi pembicaraan. Tipe yang paling sedikit adalah Tipe
Skizofrenia Simpleks $(1,04 \%)$ memiliki ciri gejala negatif yang lebih menonjol selanjutnya tipe yang tak tergolongkan berbeda dengan tipe lain skizofrenia tipe ini gejalanya sulit untuk digolongan dengan skizofrenia lain ${ }^{[9]}$ pada penelitian Ini terdapat $1,04 \%$.

Tabel 2. Penggunaan Antipsikotik pada pasien Skizofrenia di RSJD Atma Husada Mahakam Samarinda

\begin{tabular}{|c|c|c|c|}
\hline $\begin{array}{c}\text { Jenis } \\
\text { Skizofrenia }\end{array}$ & Kategori Antipsikotik & Obat & $\begin{array}{c}\text { Jumlah } \\
\text { pemakaian }\end{array}$ \\
\hline \multirow{14}{*}{ Tak Terinci } & Tunggal & & \\
\hline & \multirow{3}{*}{ AGP } & Haloperidol & 6 \\
\hline & & Chlorpromazine & 5 \\
\hline & & Aripiprazole & 1 \\
\hline & \multirow{3}{*}{ AGK } & Risperidone & 21 \\
\hline & & Clozapine & 12 \\
\hline & & Olanzapine & 1 \\
\hline & Kombinasi & & \\
\hline & \multirow{2}{*}{$\mathrm{AGP}+\mathrm{AGP}$} & Trifluoperazine + Chlorpromazine & 1 \\
\hline & & Aripiprazole + Haloperidol & 1 \\
\hline & \multirow{2}{*}{$\mathrm{AGK}+\mathrm{AGK}$} & Risperidone + Clozapine & 5 \\
\hline & & Chlorpromazine + Risperidon & 4 \\
\hline & \multirow[t]{2}{*}{$\mathrm{AGP}+\mathrm{AGK}$} & Haloperidol + Clozapine & 4 \\
\hline & & Trifluoperazine + Clozapine & 1 \\
\hline \multirow{7}{*}{ Hebefrenik } & Tunggal & & \\
\hline & \multirow[t]{2}{*}{ AGP } & Haloperidol & 2 \\
\hline & & Clozapine & 1 \\
\hline & AGK & Olanzapine & 1 \\
\hline & \multicolumn{3}{|l|}{ Kombinasi } \\
\hline & \multirow{2}{*}{$\begin{array}{c}\mathrm{AGK}+\mathrm{AGK} \\
\mathrm{AGP}+\mathrm{AGK}\end{array}$} & Risperidone + Clozapine & 1 \\
\hline & & Chlorpromazine + Risperidon & 1 \\
\hline \multirow{10}{*}{ Paranoid } & \multicolumn{3}{|l|}{ Tunggal } \\
\hline & \multirow{3}{*}{ AGP } & Haloperidol & 5 \\
\hline & & Trifluoperazine & 1 \\
\hline & & Aripiprazole & 1 \\
\hline & \multicolumn{3}{|l|}{ Kombinasi } \\
\hline & $\mathrm{AGP}+\mathrm{AGP}$ & Haloperidol + Chlorpromazine & 1 \\
\hline & \multirow{2}{*}{$\mathrm{AGK}+\mathrm{AGK}$} & Risperidone + Clozapine & 4 \\
\hline & & Risperidone + Olanzapine & 1 \\
\hline & \multirow{2}{*}{$\mathrm{AGP}+\mathrm{AGK}$} & Chlorpromazine + Risperidon & 2 \\
\hline & & Chlorpromazine + Clozapine & 1 \\
\hline \multirow{2}{*}{ Simpleks } & \multicolumn{3}{|l|}{ Tunggal } \\
\hline & AGK & Clozapine & 1 \\
\hline \multirow{2}{*}{$\begin{array}{c}\text { Yang Tak } \\
\text { Tergolongkan }\end{array}$} & \multicolumn{3}{|l|}{ Kombinasi } \\
\hline & $\mathrm{AGP}+\mathrm{AGP}$ & Haloperidol + Chlorpromazin & 1 \\
\hline
\end{tabular}




\section{Pola Penggunaan Antipsikotik pada pasien Skizofrenia berdasarkan jenis Skizofrenia}

Pola pengobatan berdasarkan jenis Skizofrenia pada pasien Skizofrenia di RSJD Atma Husada Mahakam Samarinda dapat dilihat pada tabel 2.

Tipe Skizofrenia terbanyak adalah Skizofrenia tak terinci yaitu $68 \%$. Skizofrenia tak terinci (Undifferentiated) ditandai dengan gejala positif yang menonjol atau memenuhi kriteria umum untuk diagnosis skizofrenia, tetapi tidak memenuhi kriteria untuk diagnosis skizofrenia paranoid, hebefrenik, katatonik, residual dan depresi pascaskizofrenia ${ }^{[9]}$

Pemberian obat antipsikotik tunggal pada jenis Skizofrenia tak terinci terbanyak adalah Risperidone. Risperidone adalah antipsikotik atipikal benzisoxazole dengan aktivitas antagonis serotonin-dopamin campuran yang berikatan dengan reseptor 5-HT2 di CNS dan di pinggiran dengan afinitas yang sangat tinggi berikatan dengan reseptor dopamin-D2 dengan afinitas yang lebih sedikit. Afinitas pengikatan pada reseptor dopamin-D2 adalah 20 kali lebih rendah daripada afinitas 5-HT2. Penambahan antagonisme serotonin ke antagonisme dopamin (mekanisme neuroleptik klasik) untuk mengatasi gejala positif pasien Skizofrenia namun dapat gejala negatif psikosis dan mengurangi timbulnya efek samping ekstrapiramidal. $\alpha 1, \quad \alpha 2$ adrenergik, dan reseptor histaminergik juga diantagonis dengan afinitas tinggi. Risperidone memiliki afinitas rendah hingga sedang untuk reseptor 5-HT1C, 5HT1D, dan 5-HT1A, afinitas yang lemah untuk D1 dan tidak ada afinitas untuk reseptor muskarinik atau $\beta 1$ dan $\beta 2^{[4]}$.

Pemberian obat antipsikotik kombinasi pada jenis Skizofrenia tak terinci terbanyak adalah Risperidone + Clozapine. Clozapine merupakan antipsikotik generasi kedua yang termasuk kelas dibenzodiazepin, merupakan neuroleptik atipikal D4 dan afinitas rendah untuk subtype lain, antagonis di $\alpha$-adrenoreseptor, reseptor 5 HT2A, reseptor muskarinik, dan reseptor hitamin $\mathrm{H} 1{ }^{[4]}$. Clozapine bekerja dengan menduduki reseptor D2 hanya sekitar 38 sampai $47 \%$. Clozapine dapat mengurangi perilaku bunuh diri dan efektif untuk mengatasi gejala positif dan negatif pada pasien dengan Skizofrenia yang sulit disembuhkan ${ }^{[3]}$. Kombinasi clozapine + risperidone efektif digunakan karena risperidone menduduki reseptor D2 (63 sampai 89\%), sehingga dengan penambahan risperidone diharapkan mampu meningkatkan respon terhadap clozapine $^{[7]}$.

Tipe Skizofrenia paranoid merupakan tipe yang terbanyak kedua yaitu $16 \%$. Ciri utama tipe ini menunjukkan gejala waham (delusion) kejar atau waham kebesaran atau keyakinan yang tidak rasional, misal sebagai utusan penyelamat bangsa, waham cemburu, waham dapat berupa hampir setiap jenis, namun waham dapat dikendalikan, fungsi kognitif dan afek yang relatif masih terjaga, gejala halusinasi yang menonjol seperti halusinasi pembauan atau pengecapan rasa, halusinasi visual mungkin ada tetapi jarang menonjol, halusinasi auditorik berupa bunyi tawa atau mendengung dan gangguan alam perasaan dan perilaku, misalnya kecemasan yang tidak menentu, kemarahan, suka bertengkar, dan tindak kekerasan ${ }^{[9]}$.

Pada tabel 2 pemberian obat antipsikotik tunggal yang terbanyak pada jenis Skizofrenia paranoid adalah Haloperidol. Haloperidol adalah obat antipsikotik generasi pertama bekerja dengan cara memblokade reseptor dopamine pada reseptor pasca sinaptik neuron diotak, khususnya di system limbik dan system ekstrapiramidal (reseptor Dopamin $\mathrm{D}_{2}$ antagonis). Haloperidol sangat efektif dalam mengobati gejala positif pada pasien Skizofrenia, seperti mendengar suara, melihat hal-hal yang aneh. Haloperidol 
efektif pada pasien dengan gejala dominan gaduh, gelisah, hiperaktif dan sulit tidur yang dikarenakan halusinasi [13].

Pemberian obat antipsikotik kombinasi terbanyak pada jenis Skizofrenia paranoid adalah risperidone + clozapine. Hal ini dikarenakan kombinasi antipsikotik generasi kedua dapat memperbaiki gejala positif dan negatif dari Skizofrenia dan lebih efektif mengobati pada pasien yang resisten ${ }^{[16]}$.

Tipe ketiga terbanyak adalah Skizofrenia tipe hebefrenik yaitu $14 \%$ ditandai dengan gejala-gejala: pemalu, senang menyendiri, jalan pikiran yang kacau, alam perasaan yang datar tanpa ekspresi atau ketolol-tololan, perilaku dan tertawa kekanak-kanakan, pembicaraan kacau dapat disertai kekonyolan atau tawa yang tidak berkaitan dengan isi pembicaraan $^{[1]}$, halusinasi, waham, dan menunjukkan perilaku aneh ${ }^{[6]}$.

Pemberian obat antipsikotik tunggal terbanyak pada tipe Skizofrenia hebefrenik adalah haloperidol. Haloperidol adalah antipsikotik butyrophenone yang memblok dopaminergik resep D1 dan D2 dopaminergik pascainaptik di otak penurunan neurotransmisi dopaminergik diotak meningkatkan fungsionalitas yang lebih baik pada level perseptual dan mengobati gejala positif, menekan pelepasan hormon hipotalamus dan hipofisis, dipercaya dapat menekan sistem pengaktif retikuler sehingga mempengaruhi metabolisme basal, suhu tubuh, terjaga, nada vasomotor, dan emesis.

Tipe yang paling sedikit adalah Skizofrenia simpleks yaitu $1 \%$. Tipe ini menunjukkan gejala: perilaku aneh, tidak terdapat waham atau halusinasi, gejala negatif yang menonjol misalnya: perambatan psikomotorik, aktivitas menurun, afek yang menumpul, sikap pasif, dan ketiadaan inisiatif, kemiskinan dalam kuantitas isi pembicaraan, komunikasi non verbal yang buruk seperti ekpresi muka, kontak mata, modulasi suara dan posisi tubuh, perawatan diri dan kinerja sosial yang buruk sehingga menarik diri secara social $^{[9]}$.

Pada tipe Skizofrenia simpleks obat antipsikotik yang digunakan adalah clozapine. Clozapine bekerja pada beberapa reseptor neurotransmitter seperti reseptor 5-HT1A dan 5-HT2, D1 dan D2, histamine 1 dan adrenergik $(\alpha 1$ dan a2) sehingga memiliki efek teraupetik dalam mengatasi gejala kognitif dan negatif seperti kemampuan dalam bersosialisasi pada pasien Skizofrenia ${ }^{[6]}$.

Skizofrenia yang tak tergolongkan yaitu $1 \%$ tipe ini tidak dapat dimasukkan dalam tipe-tipe yang telah diuraikan, hanya gambaran klinisnya terdapat waham, halusinasi, inkoheransi atau tingkah laku kacau ${ }^{[9]}$.

Antipsikotik yang diberikan pada tipe Skizofrenia tak tergolongkan adalah kombinasi antipsikotik generasi pertama, Haloperidol + chlorpromazine. Haloperidol + clozapine memiliki mekanisme kerja sebagai antagonis reseptor D2 dan D3 yang merupakan antipsikotik generasi pertama yang mampu mengatasi gejala positif pada pasien Skizofrenia, tetapi kurang mengatasi gejala negatif ${ }^{[17]}$. Haloperidol merupakan antagonis reseptor D2 paling kuat tetapi efek terhadap system otonom, efek antikolinergik dan efek samping sedatif lemah, sedangkan chlorpromazin bekerja pada beberapa reseptor seperti reseptor dopamine, muskarinik, kolinergik, adrenergik $(\alpha 1)$ dan histaminergik (H1) serta memiliki efek sedatif kuat yang dapat mengatasi gejala positif ${ }^{[18]}$. Kombinasi antara chlorpromazine dengan haloperidol bertujuan untuk memperkuat khasiat antipsikotik untuk mengatasi gejala positif dan efek sedatif ${ }^{[7][12]}$. Penggunaan chlorpromazine dapat menyebabkan pasien mengalami peningkatan perasaan 
sulit bergaul dalam kehidupan sosial, dan merasa khawatir terhadap masa depan ${ }^{[6]}$.

Penggunaan kombinasi antipsikotik akan menghasilkan target reseptor yang bervariasi dan lebih besar sehingga dapat meningkatkan khasiat antipsikotik dengan meningkatnya antagonis reseptor D2 dopaminergik secara aditif dan diharapkan dapat mengurangi efek samping yang terkait dengan dosis masing-masing obat ${ }^{[21]}$.

\section{KESIMPULAN} adalah:

Kesimpulan dari penelitian ini

1. Persentase Karakteristik pasien Skizofrenia pada distribusi jenis kelamin pada laki-laki $71,3 \%$ dan pada perempuan $28,7 \%$. Distribusi usia paling banyak laki-laki 26-35 tahun $24,5 \%$ dan pada perempuan 36-45 tahun $11,7 \%$. Distribusi berdasarkan pekerjaan yang paling banyak Swasta 23,4\%. Dan distribusi berdasarkan jenis Skizofrenia yang paling banyak jenis Skizofrenia Tak Terinci $68 \%$.

2. Pola pengobatan pada skizofrenia tak terinci lebih banyak diberikan risperidone pada terapi tunggal dan kombinasi yang banyak diberikan adalah risperidone + clozapine. Skizofrenia paranoid lebih banyak diberikan haloperidol pada terapi tunggal, dan risperidone + clozapine pada terapi kombinasi. Skizofrenia hebefrenik antipsikotik yang banyak digunakan adalah haloperidol pada pemberian tunggal, Skizofrenia simpleks terapi yang diberikan adalah clozapine, dan pada skizofrenia yang tak tergolongkan terapi yang diberikan adalah haloperidol dan chlorpromazine.

\section{DAFTAR PUSTAKA}

[1] Arif, I. M., 2006. Skizofrenia Memahami Dinamika Keluarga Pasien, Penerbit Refika Aditama, Bandung.
[2] Ballon, J., Stroup, T. S. 2013. Polypharmacy for Schizophrenia. Current Opinion in Psychiatry, 26 (2), 208-213

[3] Depkes RI. Laporan Hasil Riset Kesehatan Dasar Indonesia tahun 2016. Jakarta: Badan Penelitian dan Pengembangan Kesehatan Depkes RI; 2016.

[4] Dipiro, J.T., Talbert, R.L., Yee, G.C., Matzke, G.R., Wells, B.G., Posey, L.M. 2009. Pharmacotherapy A pathophysiological approach seventh edition, The McGraw-Hill Companies, Inc United States.

[5] Fahrul, A. Mukaddas., I. Faustine. 2014. Rasionalitas Penggunaan Antipsikotik pada Pasien Skizofrenia di Instalansi Rawat Inap Jiwa RSD Madani Provinsi Sulawesi Tengah Periode Januari-April 2014. Jurnal of Natural Science. 3 : 18-29.

[6] Fujimaki, K., T. Takahashi S. Morinobu., 2012. Association of Typical Versus Atypical Antipsycotics with Symthoms and Quality of Life in Schizophrenia. Influence of Antipsychotics in Schizophrenia. 7:1-10

[7] Gibson, A.P., Patel, N.C., \& Laurillo, J. 2008. Antipsychotic Combinations Blind Step or Logical, Thought Unsupported by Evidence, Using Antipsychotic May Make Sense for Some Treatment-Resistant Patients. Current Psychiatry, 7(7),40

[8] Hariyani., F. Yuliastuti., S. Morinoobu.,2012. Association of Typical versus Atypical Antipsychotics with Symptoms and Quality of Life in Schizophrenia in Schizophrenia. 7:1-10

[9] Hawaris, D., 2007. Pendekatan Holistik pada Gangguan Jiwa Skizofrenia Edisi 2, Balai Penerbitan, Kedokteran Universitas Indonesia, Jakarta

[10]Ikawati, Z., 2014. Farmakoterapi Penyakit Sistem Syaraf Pusat. Yogyakarta: Bursa Ilmu. 
[11] Irmansyah. 2004. Pencegahan dan Intervensi Dini Skizofrenia. Jakarta

[12] Jusnita， N.N., Hidajat, L.L. 2013. Profil Kepribadian dan Psychological Well-Being Caregiver Skizofrenia. Jurnal Soul. 6 : 21-42

[13] Khaira, N.R., A. Nugroho., A. Saputra. 2015. Drug Related Problems Anti Psikotik pada Pasien Skizofrenia Paranoid Akut di RS Jiwa X Jakarta. Farmasains. 2: 275280.

[14]Kemenkes RI. Laporan Hasil Riset Kesehatan Dasar (Riskesdas) Indonesia tahun 2013. Jakarta : Badan Penelitian dan Pengembangan Kesehatan Kemenkes RI ; 2013

[15]Lehman, A.F., J.A. Lieberman, L.B. Dixon, T.H. Mc Glaxhan., A. L. Miller., D. O. Perkins.,Kreyenbuhl, j.. 2004. Practice Guideline for the Treatment of Patient with Schizophrenia Second Edition. American Psychiatric Association, American.

[16]Maramis. 2009. Catatan Ilmu Kedokteran Jiwa. Edisi 2. Surabaya: Airlangga
[17]Ren, Y., H.wang., Xiao,L. 2013. Improving Myelin OligodendrocyteRelated Dysfunction: A new Mechanism Of Antipsychotics In The Treatment Of Schizophrenia. International Journal of Neuropsychopharmacology. 16:691700

[18]Saputri, Dwi. 2017. Pengaruh pemberian kombinasi antipsikotik terhadap efek samping sindrom ekstrapiramidal pada pasien Skizofrenia di Rumah Sakit Jiwa Sambang Lihum. Jurnal Farmaka. vol 15 no. 3

[19]Seeman., M. V., 2013. Women and Schizophrenia: New Findings. Neuropsychiatry. 3: 423-431

[20] Sutardjo A. Wiramihardja. 2015. Pengantar Psikologi Abnormal Edisi Revisi. Rafika Aditama; Jakarta.

[21] Tadjuddin, A. R. Padma, S. S.. 2014. Gambaran Tingkat Spiritualitas pada Orang dengan Skizofrenia (ODS) di Poliklinik Rawat Jalan RSJD Dr. Amino Gondohutomo Semarang. Jurnal Jurusan Keperawatan. 1 : 18. 